\title{
MÚSICA E EDUCAÇÃO: POÉTICAS DA ESCUTA
}

\author{
"o batuque é um privilégio, ninguém aprende samba no colégio"1
}

Organizar esta edição temática é motivo de grande satisfação e alegria, uma vez que divulgar a produção científica na área da Música e da Educação é abrir possibilidades e gerar diálogo. Em seu conjunto, este número da revista pretende constituir um processo de mediação entre ação e reflexão da práxis pedagógica, para enfrentar as ambiguidades do tema e compartilhar cumplicidade de aprendizados que permitam interrogar o encontro entre Música e Educação na contemporaneidade.

Neste contexto, a publicação da edição Música e Educação: poéticas da escuta tem a intenção de contribuir com o debate em torno do advento da lei 11.769/08, que torna obrigatório o Ensino de Música na escola brasileira. Diante da magnitude de tal desafio, nos aliamos com outras universidades e ao conjunto da sociedade para disponibilizar e enfatizar o fato de pensar uma ação possível e, do mesmo modo, necessária. Será que ninguém aprende samba no colégio? O dito de Noel Rosa e Vadico, entoado no ano de 1932, pode indicar uma afirmação corrente? Lentamente, podemos observar as universidades de música no Brasil ampliarem o seu currículo acadêmico para que o batuque deixe de ser um privilégio. Mas, como articular tal mudança se grande parte do corpo docente universitário é formado por professores que dominam apenas a música européia? Nessa direção, também podemos observar que os cursos de Pedagogia gradualmente passam a oferecer um espaço dedicado à dimensão sonora na formação de professores. Embasado em quais pressupostos teóricos surgem essas iniciativas?

Se considerarmos que uma das grandes funções da música na escola (entre tantas outras daí decorrentes) seria oferecer meios de expressão à capacidade criadora e à aprendizagem da escuta, como estamos movimentando a "colcha de recados" (WISNIK, 2004) que é a música brasileira? Ausente dos currículos escolares e da formação de professores, os quais poderiam ser os portadores vivos de nossa diversidade cultural, a música brasileira, acaba pobremente substituída por uma cópia desbotada do colonialismo musical que invade o "rádio corredor" de nossas escolas. Logo, comprometidos com a discussão dessas problemáticas nas áreas da Música e da Educação, compreendidas em sua historicidade e complexidade, nos arriscamos a escrever e pensar - sem receita - para intensificar esse encontro e acolher dissonâncias.

\footnotetext{
${ }^{1}$ Feitio de Oração, canção de Noel Rosa e Vadico.
} 
Aproximar Música e Educação é tão encantador como tenso. Supõe enfrentar as fronteiras hierárquicas e as oposições sedimentadas pelo senso comum: do sonoro e do musical, do sensível e do inteligível, do corpo e da razão, dos saberes da academia e daqueles que estão para além e aquém de seus muros. A miríade significativa do encontro entre Música e Educação incorpora a intencionalidade de aceitar o combate. Para os músicos, congelar a palavra no texto escrito pode ser um desafio. Ancorados na performance aural que se dissipa na ressonância física, têm ao seu dispor a possibilidade de fazer a cada execução mais uma vez, de outra forma, com outro sentido. Para os educadores, perder-se na palavra, sair da receita, deixar a prescrição, pode ser um convite. Para ambos, enfrentar a ambiguidade imanente e compartilhar sentidos experimentados com outras áreas do conhecimento é uma estratégia a constituir. Encantamento e tensão acolhem a surpresa, os modos de fazer que sustentam o repertório de viver e podem redimensionar o fazer cotidiano pedagógico de cada um, porque podem transcender a oposições simplificadoras.

Como fenômeno social, a música favorece interrogações difíceis de separar daquelas articuladas pela Educação. A autonomia garantida aos sistemas educacionais na organização de seus currículos em música (Lei 11.769/08) pretende indicar que ela, como prática social, "agrega aspectos que transcendem suas dimensões estruturais estéticas", estendendo-as ao "complexo sistema social e cultural que congrega aspectos estabelecidos e compartilhados pelos seus praticantes, individual e coletivamente" (QUEIROZ, 2011, p.19). Assim, assistimos a presença da música na escola tanto em sua forma curricular como extracurricular, na pluralidade e diversidade de contextos, práticas, significados e funções nas quais é produzida.

Logo, Música e Educação afinam e desafinam. Perseguem o gesto do encontro, porque a poética da escuta se dá nos contextos de socialização múltiplos e heterogêneos nos quais seus "atores plurais" (LAHIRE, 2001) participam, ao viverem diferentes deslocamentos instituídos cotidianamente. Nesse sentido, renunciar a ilusória concepção de que o mundo social seria coerente e unificado emerge para destacar que existe uma singularidade individual na escala de indivíduos socializados. Segundo Lahire (2001), o "ator plural" é portador de um sistema de disposições e competências, aceitando a pluralidade das lógicas efetivas da ação e das formas de relação com a ação, fazendo surgir o imprevisível, o indeterminado, o inesperado. Apesar das resistências, Música e Educação corrompem a consonância porque são da ordem do movimento de Ser no mundo. Embora tendam a permanecer conceitualmente separadas, as questões em jogo entrelaçam uma e outra, envolvendo contextos de significação, hierarquizações e oposições impostas socialmente. 
Compreendo que o sonoro é da ordem do movimento, território que escapa ao controle porque tem como personagem o ruído como elemento de renovação do discurso musical movimento que é presença do tempo no espaço. Attali (1977, p.9) afirma que "com o ruído nasce a desordem e seu oposto: o mundo". É o apelo à ordem que faz a música esta organização concebida pelo humano de sons e silêncios. Se pensarmos que a concepção de música distinta e independente da vida cotidiana somente foi possível pela atribuição que os povos antigos lhe conferiram, podemos sublinhar que a música como tal é conservadora. A música guarda uma memória, congela um tempo, define uma fôrma, apresenta um ponto de vista, descreve um mundo.

Com os primeiros agrupamentos humanos, a música conquistou um espaço próprio e transcendente por lhe ser atribuída o poder sagrado, também reservado aos sacerdotes. Esses últimos trataram de usar a música para enriquecer o mistério de seus ritos, concebendo-a como algo fantástico, sobreposto ao real, mundo inviolável e protegido. Nesse caso, a música apenas era possível aos bruxos, e mais tarde, aos músicos (GÁMES, 2012, p. 12). Na Idade Média, a música era o que imitava a perfeição da natureza, ajudando a 'semear' a palavra de Deus, como prova e expressão sensível da onipotência e majestade divina. Com função extra musical, sendo composta para situações específicas, a música emoldurava sonoramente um texto, carregado de significado ético-moral e religioso (LAZZARIN, 2011).

A corte e a igreja, sabiamente, encheram seus 'templos' com música por compreenderem que sua polifonia tinha o poder de embriagar os ouvidos dos cidadãos, conquistando a subversão domesticada preterida. Na corte a finalidade da música era entretenimento e status; na igreja a música estava a serviço da ideologia moral-religiosa. É com música, que os sacerdotes jesuítas determinavam a separação entre os índios colonizados e os 'rebeldes'. O sino separava a música para a alma (fiel à escrita da partitura, presa ao rigor indicado pelo compositor, perfeita e em contato com Deus), daquela música improvisada e inventiva, composta espontaneamente pelos índios, sujeita ao corpo, ou seja, carne sujeita ao pecado (LAZARRIN, 2011).

Durante o século XVIII, a música incorpora seu caráter autônomo, sendo concebida como o resultado de uma experiência estética separada do cotidiano. Nesse momento, surgem as salas de concerto, espaços destinados a 'audiência silenciosa' da obra musical. O silêncio requerido nessas práticas musicais exige a presença de um corpo contemplativo, impedindo que esse último, como gestação do incerto, experimente a demasiadamente humana sensação de ignorância. 
A música no século XX irrompe ruidosamente em contraponto a toda esta efeméride de conceitos, desassossegando à escuta de um corpo paralisado ao indicar que o ruído provoca disposição à ação. Nietzsche (1993, p. 32) afirma que o ouvido, "este órgão do medo, só alcançou tamanha grandeza na noite escura e na penumbra de cavernas obscuras e florestas". Esse ouvido tinha um modo de tocar o mundo que, longe de ser um ato passivo de incorporação da paisagem sonora, implicava a habilidade de interpretar informações sobre sua tranquilidade ou perigo. Nesse contexto, a habilidade auditiva impunha-se como uma necessidade vital àquela sociedade.

Há cem anos atrás, em 1913, Russolo escrevia "A arte dos ruídos", manifesto para colocar em pé de igualdade o ruído com o resto das sonoridades tradicionalmente identificadas como musicais. Com a invenção das máquinas nascia a inclusão do ruído como elemento de representação dos novos tempos e a escuta do mundo cotidiano, uma afirmação de identidade. Nesse instante, diferentes grupos e compositores debatem, provocam e compõem reflexões sonoras para interrogar as fronteiras entre o sonoro e o musical. John Cage (1957) afirma que não existe silêncio. O compositor aponta que não é necessário nos preocuparmos com o futuro da música. As sonoridades continuarão após nossa morte. Schafer (1991) alerta para a necessidade da escuta e do ouvido pensante, mobilizando a audição da paisagem sonora. Nesse painel, emerge a Arte Sonora como cenário do movimento de Ser sonoro, lugar plástico que acolhe hibridamente o som, o tempo, o espaço e o lugar. Modo de constituir um contexto no qual o ouvinte participa da performance, dissociado da obra musical de cunho contemplativo.

A música causa ressonância que, segundo Nancy (2007) é o som do sentido. O corpo incorpora a materialidade dessa ação, fazendo com que a possibilidade de sentido se identifique com a possibilidade da ressonância. A poética da escuta é, pois, o som do sentido, vigor da ação. Não é discurso sobre o mundo, mas ação no mundo. Um agir que ao agir transforma o que toca, expressando a potência da humana transformação de fazer estranho o familiar. Os gregos usavam a palavra "poiesis na pluralidade de acepções que dinamizam o estar no mundo, isto é, a vida cotidiana do agir, produzir, criar. (...) Trata-se de um fazer inseparável do fazer-se, pois mais que construir e realizar, o humano se faz em produção. $\mathrm{O}$ devir humano é antes de mais nada criador" (RICHTER, 2008, p. 22). Nessa perspectiva, provar excessos, organizar espaços para a experiência "estético/poética" (BOURSCHEID, 2014) é resgatar da evidência do trivial para transformar o inesperado em extraordinário.

No Brasil, a música já esteve presente na escola em vários momentos com funções e significados específicos. Considerados os escapes e as singularidades sonoras sempre 
possíveis, poderíamos dizer que, historicamente, a música aparece no currículo escolar com objetivo religioso, no século XVIII, conduzida pelos jesuítas. Para aprender a solfejar e cantar, passa a ser ministrada por professores especialistas, no século XIX. Atendendo ao civismo e a disciplina, a música irrompe nas escolas no século $\mathrm{XX}$, com o canto orfeônico. Como uma disciplina polivalente ocorrendo de forma superficial, a música acontece nos anos 1970 (BRASIL, 71), sendo conduzida por um professor licenciado "polivalente" (habilitado em Música, ou Artes Plásticas ou Teatro). A música se insere como conteúdo obrigatório do Ensino de Arte nos anos 1990 (BRASIL, 1996), sem a indicação do tipo de profissional ou da área artística contemplada. Por fim, a música aparece como conteúdo curricular obrigatório na educação básica em 2008, mas não exclusivo, do componente curricular Arte, através da implementação da Lei 11.769/08 (FIGUEIREDO, 2011, p. 5).

Os distintos sotaques sonoros tonalizados pela Música e Educação na escola supõem interrogações e não respostas; exigem investigação e não explicações; reivindicam a escuta, para não impor modelos prévios. O intenso movimento de valorizar a escuta vem nos mostrando que seus princípios de complexidade, de abstração das realidades e de interpretação apresentam a potência de considerar os fatores de heterogeneidade que as geram.

Ou, nas palavras do poeta:

(...) me entristece o quanto fomos deixando de escutar. Deixamos de escutar as vozes que são diferentes, os silêncios que são diversos. E deixamos de escutar não porque nos rodeasse o silêncio. Ficamos surdos pelo excesso de palavras, ficamos autistas pelo excesso de informação. A natureza converteu-se em retórica, num emblema, num anuncio de televisão. Falamos dela, não a vivemos. (COUTO, 2005, p. 123).

Só conhece o som aquele que vive o som. Somos sonoridade em cada ato. Nascemos chorando. Crescemos brincando intensamente com os sons. Morremos dando o último suspiro. As músicas "(...) são criações que não necessitam ser traduzidas nem transferidas, nas quais o corpo é a ferramenta e a conclusão, o princípio e o fim, a partitura escrevendo-se e soando" (MARGARIT, 2012, p. 45). Para potencializar a reflexibilidade desses princípios, decorrentes de uma abordagem plural de Música e Educação é que propusemos o tema desta edição, articulando pesquisas e discussões que contribuam com a complexidade educacional da temática. A edição está organizada com um ensaio, 10 artigos temáticos, três artigos especiais, uma entrevista e um relato de experiência. Os autores são provenientes de diferentes áreas do conhecimento, oriundos de diversas regiões do Brasil e exterior. 
O ensaio em forma de prelúdio que abre a edição é do destacado compositor canadense Murray Schafer: Sound Around. As revolucionárias proposições do também artista plástico têm mobilizado uma ampla rede de formação de professores porque o músico constrói a noção de paisagem sonora, ouvido pensante e poluição sonora. Ao dedicar grande parte de sua vida aos problemas do ensino de música, Schafer desafia nossa escuta, reivindica a catalogação dos sons que já nos atravessaram e afirma que estamos condenados a ouvir. Afinal não temos pálpebras em nossos ouvidos! Seu fascinante itinerário de pesquisador tem contribuído para pensar uma educação musical comprometida com o fazer criativo como elemento central dos currículos.

Marisa Trench de Oliveira Fonterrada, pesquisadora do Programa de Pós-Graduação Mestrado e Doutorado em Música do Instituto de Artes do Planalto, UNESP-SP, responsável no Brasil pela tradução e divulgação de experiências fundantes do trabalho de Murray Schafer, apresenta o artigo intitulado: A música em tempos de mudança - reflexão acerca de seu papel na educação. A destacada musicalizadora aborda a implementação da Lei 11,769/2008 - que torna obrigatório o ensino de música na educação básica - e a nova condição dos professores das séries iniciais. Fonterrada nos convida a acolher a música em nossas vidas e compartilhá-la com nossos alunos; além de sugerir formas de tornar a música presente na sala de aula.

Encontros estéticos/poéticos entre música e bebês na creche de Sandra Richter e Clarice Bourscheid, narra a escuta fenomenológica experimentada pelas pesquisadoras na escola de Educação Infantil. Vinculadas ao Programa de Pós-Graduação em Educação da Universidade de Santa Cruz do Sul (UNISC), as professoras abordam a intimidade entre as dimensões estética e poética nos encontros experimentados entre música e bebês na creche, partindo da compreensão merleaupontiana do corpo sensível. A interlocução a pesquisadora de arte e infância com a cantora-professora de bebês, permite afirmar a potência vital e lúdica do corpo expressivo sentir a si próprio e ao mundo na pluralidade dos modos de estar em linguagem que dinamizam a vida cotidiana do agir, produzir, criar, fazer.

O encontro dos violonistas Roberto Kittel Pohlmann e José Estevam Gava se deu no programa radiofônico Musicaos- música sem fronteiras, Projeto de Extensão da Universidade Federal de Pelotas. O artigo Por uma escuta livre sugere técnicas e estratégias para ampliar e incentivar uma forma de escuta musical mais livre e crítica. Embasada nos pressupostos teóricos de Schafer e Bachelard, o mestrando em Educação da UNISC e o professor da Universidade Federal do Paraná, propõem formas de escuta musical alternativas, desvinculadas dos meios de comunicação de massa. 
Reflexões sobre o não dito na Educação Musical: um espaço a ser ocupado pela música contemporânea tem como ponto de reflexão a diversidade nas propostas de educação musical. O artigo da pianista Érica Dias Gomes, vinculada ao Departamento de ArteEducação da Universidade Estadual do Centro-Oeste do Paraná (UNICENTRO) foca sua atenção na inserção da música erudita contemporânea, entre as infinitas possibilidades de repertório a ser utilizado na educação musical. A pesquisadora considera que este contato com o novo pode permitir a ampliação do gosto musical, desenvolvendo uma visão crítica em relações às diferentes produções musicais vigentes.

A peruana Luzmila Mendivill Trelles Correio, em Canciones y aprendizajes en educacion inicial apresenta sua investigação do cardápio sonoro escolar. Presidente Nacional do Fórum Latinoamericano de Educação Musical (FLADEM) e vinculada ao Departamento de Educação da Pontifícia Universidade Católica do Peru a pesquisadora coleta e analisa as canções entoadas pelas crianças no cotidiano da escola pública. A análise crítica do material coletado, aponta para a utilização do cancioneiro musical como ferramenta de controle simbólico, demarcador de formas de poder sobre as crianças.

Ao preocupar-se com a sistematização de propostas de educação musical para a juventude, a gaúcha, Helena Lopes da Silva, pesquisadora da Escola de Música da Universidade do Estado de Minas Gerais (ESMU/UEMG), apresenta o artigo Mediando as escutas musicais dos jovens: uma proposta para a educação musical na escola regular. Embasado na perspectiva sociológica da Pedagogia Musical, o estudo destaca a importância da multiplicidade de escutas experimentadas na aula de música. Para tanto, a educadora musical, analisa dois projetos desenvolvidos na escola: "Encontros com o compositor" e "Música na Educação de Jovens e Adultos", tecendo os sentidos da aula de música para o referido grupo.

Fruto de um trabalho de pesquisa vinculado ao Programa de Pós-Graduação em Educação da Universidade Federal do Rio Grande do Sul, o percussionista e investigador Eduardo Pacheco, da Universidade Estadual do Rio Grande do Sul, apresenta o artigo: Inventário de uma (des)educação musical. Integrado ao Observatório da Educação do MEC, vinculado à CAPES e ao INEP o presente estudo inventa novas perguntas para que as relações entre os elementos musicais possam ser experimentados. A criação é a conduta que perpassa os deslocamentos refletidos a partir do pensamento da diferença como campo conceitual que sustenta as escolhas de realização de uma intervenção pedagógica na qual a música e a infância emergem como meios de realizar uma vida que ainda está por vir. 
A utilização da música como instrumento para a prática pedagógica em sala de aula é o tema do texto Construindo competências em Geografia e História utilizando músicas na sala de aula, de Bruno Nunes Batista e Fabio Chang de Almeida. Eles justificam sua abordagem no mundo de possibilidades que o trabalho com música traz para a atividade dos(as) professores(as). Tendo como base as Matrizes Curriculares propostas pelo Exame Nacional do Ensino Médio referentes às Ciências Humanas e as Tecnologias, assim como os componentes curriculares de Geografia e História, os autores propõem um conjunto de atividades a serem realizadas pelos(as) professores(as).

Ações formativas no Projeto de Extensão Serelepe, de Eugênio Tadeu e Lorrayne Ellen, é apresentado pela Escola de Belas Artes da Universidade Federal de Minas Gerais e discute a experiência outorgada nos oito anos de realização do Projeto de Extensão 'Serelepe: uma pitada de música infantil'. Instalado no Curso de Graduação em Teatro da Universidade Federal de Minas Gerais, o estudo discute o conceito de ação formativa, partindo dos pressuposto teóricos definidos por Larossa. O referido projeto é coordenado pelo músico e teatrólogo Eugênio Tadeu e pela estudante de Teatro e bolsista Lorrayne Ellen.

$\mathrm{Na}$ seção de artigos especiais a edição apresenta três textos. O primeiro, As tecnologias da informação e da comunicação como mediadoras no processo de formação docente: um recorte nos grupos de trabalho da ANPED - 2009 a 2012, dos pesquisadores Carla Spagnolo, Ana Margô Mantovani, Bettina Steren Santos e Cesar Augusto Müller, da Pontífica Universidade Católica do Rio Grande do Sul, analisa a presença da discussão sobre as tecnologias da informação e comunicação nas reuniões da Associação Nacional de PósGraduação e Pesquisa em Educação (ANPEd), destacando os grupos de trabalho onde o tema mais se faz presente.

A escolarização da Infância: notas sobre a prática pedagógica de uma professora de jardim da infância "Getúlio Vargas", segundo artigo especial, é um estudo dos doutorandos em Educação, José Edimar de Souza e Caroline Machado Cortelini Conceição. O trabalho analisa as memórias fragmentadas de Maria Fersy Hôber Thiesen, professora do jardim da infância na cidade de Novo Hamburgo em 1942. Por fim, Daiane Kipper, Fabiane Sarmento Oliveira Fruet e Éder Julio Kinast, em Potencialidade do ensino-aprendizagem de matemática mediado pelas tecnologias na Escola Estadual de Ensino Médio Nossa Senhora do Rosário em Santa Cruz do Sul-RS, investigam o uso das Tecnologias da Informação e da Comunicação (TIC) nas séries finais do ensino fundamental.

Para enriquecer ainda mais a edição, Lydia Hortélio, experiente e dedicada pesquisadora da Música Tradicional da Infância é nossa entrevistada desta edição temática. A 
numerosa coleção documentada dos brinquedos e expressões da cultura do povo, em especial da música da cultura infantil no Brasil e ao redor do mundo, provoca nossa prática pedagógica ensinando-nos o "tom particular de cada manifestação". A conhecedora da música das crianças que sabe brincar como poucos, nos conta suas memórias sonoras, seus encontros com o brincar, projetos e indica a prática da Música Tradicional da Infância como programa ideal de iniciação à Música.

Para finalizar, apresentamos também o relato de experiência Proibido não tocar: uma instalação sonora na escola de Educação Infantil, resultado da parceria constituída entre duas universidades - Universidade de Santa Cruz do Sul (UNISC) e Universidade Federal do Rio Grande do Sul (UFRGS) - e uma escola de música, Espaço de Criação Musical. A investigadora da música na infância Dulcimarta Lemos Lino, está acompanhada de Ariane Carolina Boscardini Bittencourt, professora da Escola Municipal de Educação Infantil Zozina Soares de Oliveira com especialização em Educação Infantil para compor uma instalação sonora na escola pública. As autoras investigam as potências criadoras do barulhar a partir dessa experiência.

Ao finalizarmos esta edição fica a certeza que vivemos uma experiência estética intensa e divertida. Feito ciranda, essa revista começa com uma pequena roda que vai aumentando à medida que as pessoas chegam para dançar. Agradecemos aos Mestres da ciranda, parceiros incansáveis do Programa de Pós-Graduação da UNISC que escutaram poeticamente nossa proposta, arriscando o primeiro passo. Aos autores dos artigos que submeteram seus textos; aos convidados especiais que aceitaram estar conosco; aos técnicos que tornaram possível esse encontro; nossos cirandeiros, a admiração por manter a roda em movimento, abrindo o círculo e segurando nas mãos dos que já estavam dançando. Por fím, deixemos que a simpatia e a disponibilidade de brincar a ciranda ressoem um espaço, um tempo, um lugar no qual Música e Educação "reaprendam a criar fronteiras permeáveis que funcionem como varandas em que se produzam vizinhanças" (COUTO, 2013, p.198). Embalados nos braços da poesia, possamos encontrar sentido para superar limites que incorpo-rem escuta e criação na educação musical brasileira (...) 


\section{REFERÊNCIAS}

ATTALI, Jacques. Bruits: essai sur l'économie politique de la musique. Presses Universitaires de France: Paris, 1977.

BOURSCHEID, Clarice. Escuta Estética/Poética na Creche: encontros musicais com bebês e crianças pequenas. Dissertação de Mestrado, UNISC, 2013.

BRASIL. Lei de Diretrizes e Bases da Educação Nacional. Lei 5692/71, de 11 de agosto de 1971. Brasília, 1971. Disponível em http://www.planalto.gov.br/ccivil_03/leis/5692.htm

BRASIL. Lei de Diretrizes e Bases da Educação Nacional. LDB: Lei 9394/96. Brasília, Diário Oficial da União, Ano CXXXIV, n. 248, de 23/12/1996, pp27.83327841.

CAGE, John. Música experimental. Árdora Ediciones: Madrid, 2007.

COUTO, Mia. Se Obama fosse africano? São Paulo: Companhia das Letras, 2005.

COUTO, Mia. Pensar a Cultura. MACHADO, Cassiano Elek (Org.) Porto Alegre: Arquipélago: Editorial, 2013.

FIGUEIREDO, Sérgio. Educação Musical e Legislação Educacional. In: Salto para o Futuro. Ano XXI Boletin 08 - Junho 2011. (p.10-16)

GÁMEZ, Luis. El arte del ruido. Barcelona: Afha Decay, 2012.

LAHIRE, Bernard. L'homme pluriell. Lisboa: Instituto Piaget, 2001.

LAZZARIN, Luis Fernando. Música como ideal pedagógico: uma metáfora e uma anti (analogia). In: Questões de Música. GOBBI, Valéria (Org.), 2 edição, Passo Fundo: Editora da Universidade de Passo Fundo, 2011. p114-132

MARGARIT, Angels. Sete motivos para bailar. Barcelona: Ed. Ateneo, 2012.

NANCY, Jean Luc. A la escucha. Buenos Aires: Amorrortu, 2007.

Quinteto Violado

QUEIROZ, Luis Ricardo. Diversidade musical e ensino de música. In: Salto para o Futuro. Ano XXI Boletin 08 - Junho 2011. (p. 17-23)

RUSSOLO, Luigi. L'Arte dei rumori. Roma: Nuovi Equilibri, 2009.

SCHAFER, Murray. O ouvido pensante. São Paulo: UNESP, 1991.

WISNIK, José Miguel. Sem receita: ensaios e canções. São Paulo: Publifolha, 2004. 